\title{
Review of K. Lippert-Rasmussen's Born Free and Equal? A Philosophical Inquiry into the Nature of Discrimination
}

\author{
Serena Olsaretti \\ ICREA-Universitat Pompeu Fabra
}

\author{
Published in: \\ Analysis , 76, 1 (2016): pp. $111-113$
}

At the outset of Born Free and Equal?, Kasper Lippert-Rasmussen helpfully identifies the three central questions his book addresses: "What is discrimination?; What makes it wrong?; What should be done about wrongful discrimination?" (3). To each of these questions Lippert-Rasmussen dedicates one of the three parts into which the book is divided.

According to Lippert-Rasmussen, discrimination is differential treatment (which includes acts, policies, and practices) on the basis of real or imputed membership in socially salient groups (i.e., groups perceived membership of which structures interaction in many social contexts), which either shows a biased attitude towards those discriminated against (as in the case of direct discrimination), or which does or would result in the discriminatees' being made worse off relative to others (as with some instances of direct discrimination, and as with indirect discrimination). Although there are other types of differential treatment, including some which are wrongful, Lippert-Rasmussen justifies focusing on group discrimination as defined above on the dual grounds that this is what is often at stake in debates on discrimination, and that group discrimination is a reliable proxy for wrongful differential treatment (33).

Choosing to focus on group discrimination for these reasons may be defensible, although at times Lippert-Rasmussen's claim seems to be the conceptual claim that only group discrimination qualifies as discrimination at all (e.g. at 33 and at 95). Lippert-Rasmussen also makes other conceptual claims, such as the one, which he takes as a fixed point in two argumentative moves (at 23 and 25), that nepotism does not constitute discrimination. His definition of discrimination also excludes the possibility of what we might call Neroism - i.e., differential treatment that tracks only the discriminator's capricious moods - from qualifying as discrimination. What justifies these restrictions remains unclear.

These definitional issues raise a more general doubt about the aims of Part 1 of the book. In Part 1, Lippert-Rasmussen wants to identify "which nonmoral properties discrimination has" (14); he also wants to remain neutral between different accounts of why discrimination is wrong, examination of which he defers until Part 2. Given these two aims, it seems that he should use a very inclusive concept of discrimination (that allows nepotism, Neroism, and discrimination of people from non-socially salient groups to qualify as discrimination) so as not to bias the discussion of when and why differential treatment constitutes discrimination in the morally relevant sense in favour or against any particular account.

On Lippert-Rasmussen's view, defended in Part 2, discrimination is wrong, when it is, because it disadvantages those who are worse off than others while not being less deserving than others. This desert-prioritarian view is a particular, consequentialist, version of the harm-based account, on which discrimination is 
wrong, when it is, because it harms. The desert-prioritarian view accounts for why group discrimination seems especially important: members of socially salient groups are likely to suffer stigmatic harms and cumulative disadvantage. It also captures many of our intuitively plausible judgments about which instances of discrimination are wrong: it explains why discrimination against African Americans is wrong, while affirmative action that disadvantages the better off is not (168-9). The view does less well in accounting for the wrongness of discriminatory acts that have the effect of not harming overall, or even benefiting, their victims, as in James Woodward's (1986) case of a black would-be passenger who escapes an air-crash thanks to a racist ticket-seller's unwillingness to sell him the ticket to board the unlucky plane. Lippert-Rasmussen holds that the view can handle such cases by judging the discriminator's act by reference to the expected, rather than actual, consequences of his act (158), and/or by focusing on the harmful effects of the set of discriminatory acts (167).

Whether or not such responses are satisfactory, one could think it counts against Lippert-Rasmussen's view that it does not make the wrongness of direct discrimination depend in any way on the feature identified as distinctive of direct discrimination in Part 1 of the book, that is, the fact that it reflects a bias on the part of discriminators. Relatedly, one could think it a weakness that the account does not register any moral difference between direct and indirect discrimination (the wrongness of instances of either fully depends, on this view, on the extent to which they disadvantage worse off individuals who are not less deserving than others).

Besides defending his desert-prioritarian view, Lippert-Rasmussen also subjects to critical scrutiny competing accounts of the wrongness of discrimination, focusing mainly on two families of views which tie the wrongness of discriminatory acts to considerations about the moral status or worth of persons. On mental-states accounts (here Lippert-Rasmussen focuses mostly on Lawrence Alexander's view), the fact that discriminators have beliefs about the discriminatees' being inferior or lacking moral worth accounts for the wrongness of discrimination. On objectivemeaning accounts (here the focus is on the views of Deborah Hellman and of Thomas Scanlon), discrimination is wrong in virtue of its expressing the insulting or demeaning objective message that discriminatees are inferior to others or that they lack moral worth. Lippert-Rasmussen puts substantial pressure on these views. He challenges their defenders to offer a satisfactory account of why having even clearly false beliefs (i.e., that some persons lack moral worth) is morally wrong (with regard to mental-state views); to show that a plausible understanding of the requirement to respect equal moral worth would indict all demeaning messages (with regard to Hellman's view); and to offer a clearer and convincing picture of the relation between the wrongness of marking others as inferior and the imposition on them of disadvantages that typically accompanies so marking them (with regard to Scanlon's account).

Whether or not defenders of these accounts can meet the challenges LippertRasmussen raises for them, this book's insightful discussion of them, as well as Lippert-Rasmussen's lucid engagement with a wealth of other philosophical questions about discrimination, render Born Free and Equal? a highly valuable contribution to a relatively neglected area of ethics and political philosophy.

\section{References}

Woodward, J. 1986. The Non-Identity Problem. Ethics 96: 804-831. 